\title{
Antiknock Performance of Interlayered High-Damping-Rubber Blast Door under Thermobaric Shock Wave
}

\author{
Xiudi Li, ${ }^{1,2}$ Chaoyang Miao, ${ }^{1,2}$ Qifan Wang, ${ }^{1}$ and Zhengang Geng ${ }^{1}$ \\ ${ }^{1}$ Department of Civil Engineering, Logistical Engineering University, Chongqing 401311, China \\ ${ }^{2}$ Chongqing Key Laboratory of Geomechanics \& Geoenvironment Protection, Chongqing 401311, China
}

Correspondence should be addressed to Chaoyang Miao; zhaoyang_miao@163.com

Received 16 February 2016; Revised 24 April 2016; Accepted 4 May 2016

Academic Editor: Isabelle Sochet

Copyright (C) 2016 Xiudi Li et al. This is an open access article distributed under the Creative Commons Attribution License, which permits unrestricted use, distribution, and reproduction in any medium, provided the original work is properly cited.

The long duration and high impulse shock wave of thermobaric bomb threatens the security of underground structures. To obtain high resistance blast door against thermobaric shock wave, firstly, the dynamic mechanic property of high damping rubber was studied by split Hopkinson pressure bar (SHPB) equipment and the stress-strain relationship of high damping rubber under average strain rate of 5200/s was obtained. Secondly, the numerical model of interlayered high-damping-rubber blast door was established with ANSYS/LS-DYNA code based on test results, and the antiknock performance of interlayered high-damping-rubber blast door under thermobaric shock wave was analyzed by contrast with ordinary blast door. The results showed that the midspan displacement of the blast door decreased firstly and then increased with the increase of thickness of the high-damping-rubber interlayer, and the optimal thickness of the high-damping-rubber interlayer for energy consuming was $150 \mathrm{~mm}$ in the calculation condition of this paper. With the increase of the distance between the interlayer and the front surface of the door, the midspan displacement of the blast door decreased continually. The midspan maximum displacement of interlayered high-damping-rubber blast door decreased $74.5 \%$ in comparison to ordinary blast door. It showed that the high-damping-rubber structure can effectively improve the antiknock performance of blast door under thermobaric shock wave.

\section{Introduction}

With the rapid development of the spying and precision strike technology, precision-guided weapons pose a serious threat to the survival of fixed target such as underground protective engineering in wartime. A thermobaric weapon is a type of explosive that utilizes oxygen from the surrounding air to generate an intense, high-temperature explosion, and in practice the blast wave typically produced by such a weapon is of a significantly longer duration and higher impulse than a conventional condensed explosive. The US Army used a single $2,000 \mathrm{lb}(910 \mathrm{~kg}$ ) laser guided thermobaric bomb in Afghanis$\tan$ in 2002 against cave complexes in which Al-Qaeda and Taliban fighters had taken refuge. The long duration and high impulse shock wave of thermobaric bomb will threaten the security of underground protective engineering, especially the blast doors in tunnel.

So, to resist the destruction from high energy blast wave, the research of high resistance blast door has been a focus in protective engineering continuously. In fact, improving the structure form of blast door is an important and effective way to enhance the door resistance. Zhang proposed to set up steel plate outside the concrete filled steel tube [1] and Shi et al. put forward setting box profiled steel sheet in reinforced concrete slab to improve the door's resistance [2]. Obviously, filling the energy absorption material in the blast door is another significant way to improve the blast door's resistance. Hassan et al. studied the blast resistance of sandwich panels based on cross-linked PVC cores and aluminum alloy skins; the results showed that the foam core absorbs more than fifty percent of the overall energy [3]. Fan et al. performed a comparison of blast resistance between sandwich panels consisting of two aluminum alloy face-sheets and a honeycomb core and monolithic plates of equivalent mass; the results showed that the sandwich construction has better deformation resistance [4]. Studies from Ren et al. showed that rigid polyurethane foams, aluminum foam, and rubberized concrete filling the blast door could enhance the door's antiknock performance 


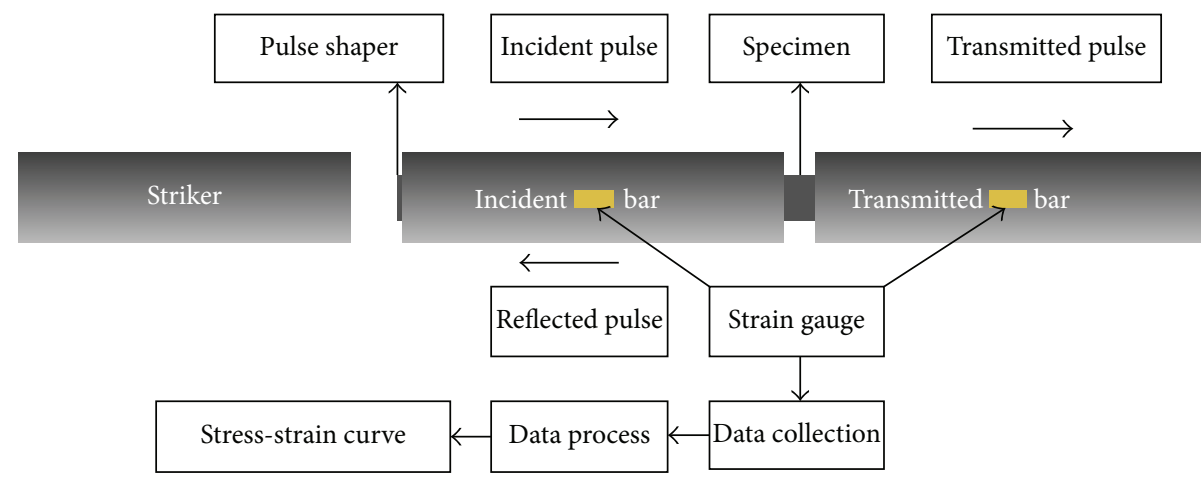

(a) Test principle

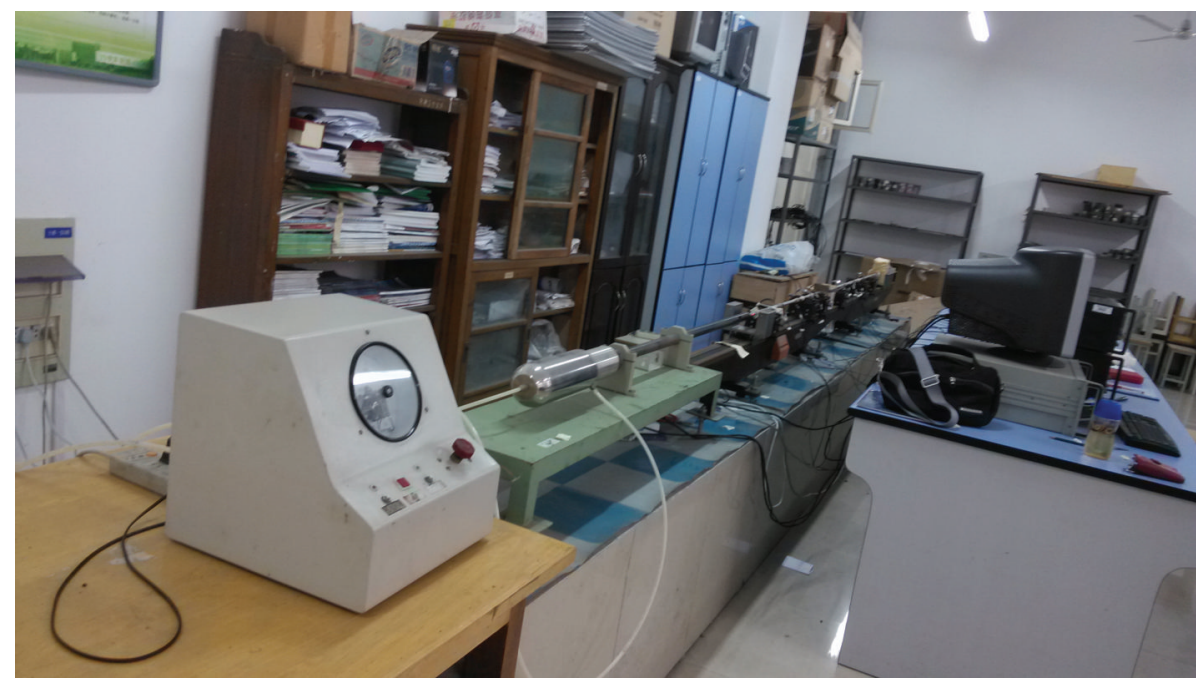

(b) Test equipment

FIgURE 1: Test equipment and principle.

$[5,6]$. High resistance blast doors mentioned above are mainly against the shock wave from conventional condensed explosive. In this paper, an antiknock sandwich structure with a new kind of energy dissipation material will be proposed to resist the damage of shock wave with longer duration and higher impulse from the thermobaric bomb.

High damping rubber is made from natural rubber adding various additives by high temperature and pressure curing. High-damping-rubber bearing has been used in shock isolation protection of Hong Kong-Zhuhai-Macao Bridge in China. High damping rubber showed good energy absorption properties. Yuan et al. studied the mechanical properties of high-damping-rubber bearing and the results showed that it is of good vibration isolation capacity [7]. Chen et al. conducted a vertical compression and shear experiment of high damping rubber and the results showed that its energydissipating capacity is still good after repeated cyclic loading [8]. It showed that high damping rubber has good energy absorption properties according to the previous researcher's works. However, it is almost blank for the application of high damping rubber in antiknock structure. So, the high damping rubber is proposed as the energy dissipation material in antiknock sandwich structure under thermobaric shock wave in this paper. Firstly, the constitutive relation of high damping rubber in high strain rate will be studied by split Hopkinson pressure bar (SHPB) experiment. Then, the antiknock performance of interlayered high-damping-rubber blast door under thermobaric shock wave will be analyzed with the finite element code ANSYS/LS-DYNA.

\section{SHPB Experiment of High Damping Rubber}

2.1. Test Program. The experiment was carried out on the split Hopkinson pressure bar in Hefei University of Technology in China. The test principle and equipment are shown in Figure 1.

Figure 1(a) shows that the incident pulse signal (denoted as $\varepsilon_{i}$ ) and reflected pulse signal (denoted as $\varepsilon_{r}$ ) are collected by the strain gauge on incident bar and the transmitted pulse signal (denoted as $\varepsilon_{t}$ ) is collected by the strain gauge on transmitted bar. The elasticity modulus, wave velocity, and cross-sectional area of bar are $E, C$, and $A$, respectively. 
The cross-sectional area and thickness of specimen are $A_{s}$ and $l_{s}$, respectively. The average strain $\varepsilon_{s}$, strain rate $\dot{\varepsilon}_{s}$, and stress $\sigma_{s}$ of specimen are as follows [9]:

$$
\begin{aligned}
\varepsilon_{s} & =\frac{C}{l_{s}} \int_{0}^{T}\left(\varepsilon_{i}-\varepsilon_{r}-\varepsilon_{t}\right) d t, \\
\dot{\varepsilon}_{s} & =\frac{2 C}{l_{s}}\left(\varepsilon_{i}-\varepsilon_{t}\right), \\
\sigma_{s} & =\frac{E A}{A_{s}}\left(\varepsilon_{i}-\varepsilon_{r}\right) .
\end{aligned}
$$

Since the wave impedance and wave velocity of high damping rubber are low, effective results will not be obtained by the traditional SHPB equipment [10]. So, the low wave impedance aluminum bars with $14.5 \mathrm{~mm}$ in diameter were used in this test. To prolong the effect time of incident wave, a long strike bar was chosen $(0.5 \mathrm{~m})$. Incident wave employed the pulse shaping technique to make the waveform rise slowly. The data of incident wave was collected by electrical resistance strain gauge on the incident bar. However, the transmitted wave which is too weak to be got was collected by semiconductor strain gauge which is of high sensitivity on the transmitted bar. The high-damping-rubber specimen is shaped as cylinder which is $8 \mathrm{~mm}$ in diameter and $2 \mathrm{~mm}$ in thickness. The thinner specimen can achieve uniform stress as soon as possible. Both ends of the specimen were homogeneously coated with a thin layer of Vaseline to reduce the influence of friction between the specimen and bars.

2.2. Test Results. The strike bar impacted the incident bar at the speed of $20.58 \mathrm{~m} / \mathrm{s}$. The typical waveform from the stain gauges on incident and transmitted bars is shown in Figure 2(a). The average strain rate of specimen can be obtained by (2). In this study, the wave velocity $C$ is $5070 \mathrm{~m} / \mathrm{s}$ and the thickness of specimen $l_{s}$ is measured by Vernier caliper. The incident pulse signal $\varepsilon_{i}$ and transmitted pulse signal $\varepsilon_{t}$ are gained by the strain gauge. The average strain rate is $5200 / \mathrm{s}$ and the engineering stress-strain relationship curve of high damping rubber at the average strain rate of 5200/s is shown in Figure 2(b).

\section{Numerical Model Establishment and Validation}

3.1. Numerical Model. A single door is chosen to analyze the antiknock performance of the interlayered high-dampingrubber blast door. For the sake of comparing, the dynamic response of ordinary reinforced concrete blast door under thermobaric shock wave is analyzed too. The length $(Y$ direction) of ordinary reinforced concrete door is $2 \mathrm{~m}$, the width ( $X$ direction) is $1.5 \mathrm{~m}$, and the thickness ( $Z$ direction) is $0.27 \mathrm{~m}$. The thickness of door frame is $60 \mathrm{~mm}$ and the width of contact between door frame and door is $50 \mathrm{~mm}$. The $\phi 18 \mathrm{HRB} 335$ tensile reinforcement ( $X$ direction) and the $\phi 12$ HRB335 distributing reinforcement ( $Y$ direction) are arranged in two layers and two ways in the direction of the length and width of blast door at the distance of $90 \mathrm{~mm}$. The $\phi$

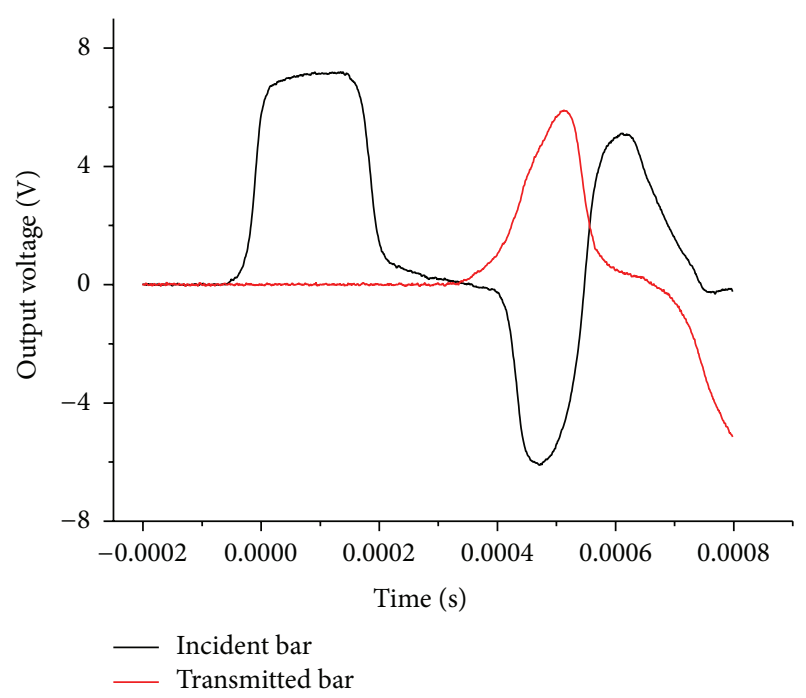

(a) Typical waveforms from incident and transmitted bars

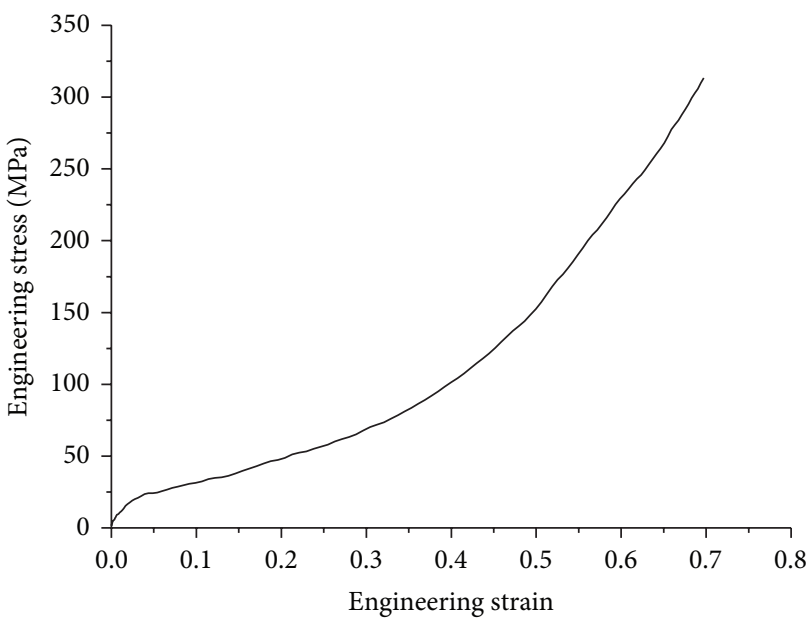

(b) Engineering stress-strain curve

FIGURE 2: SHPB test results of high damping rubber.

8HRB335 single limb stirrup ( $Z$ direction) is arranged at the distance of $180 \mathrm{~mm}$.

The interlayered high-damping-rubber blast door is a sandwich structure consisting of two reinforced concrete face-sheets and a high-damping-rubber core. Its length and width are the same as ordinary door mentioned above. For the convenience of normal use, the thickness of high-dampingrubber interlayer is set by the principle that it could improve the antiknock performance; the thickness and the overall weight of blast door do not increase. In this study, the thickness of interlayered high-damping-rubber blast door is set as $0.3 \mathrm{~m}$.

Supposing that there is no obvious slip between steel reinforcement and concrete as well as rubber and concrete under the blast wave, the common node connection is used between steel and concrete as well as rubber and concrete in the finite element model of blast door. And the same mesh size is selected to determine the position of the common nodes easily for concrete, steel reinforcement, and rubber of 


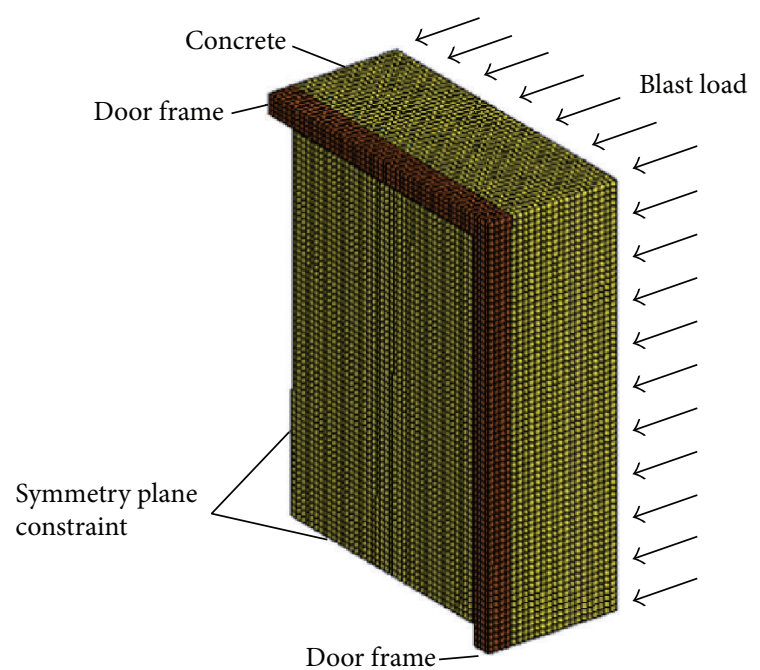

Ordinary reinforced concrete blast door

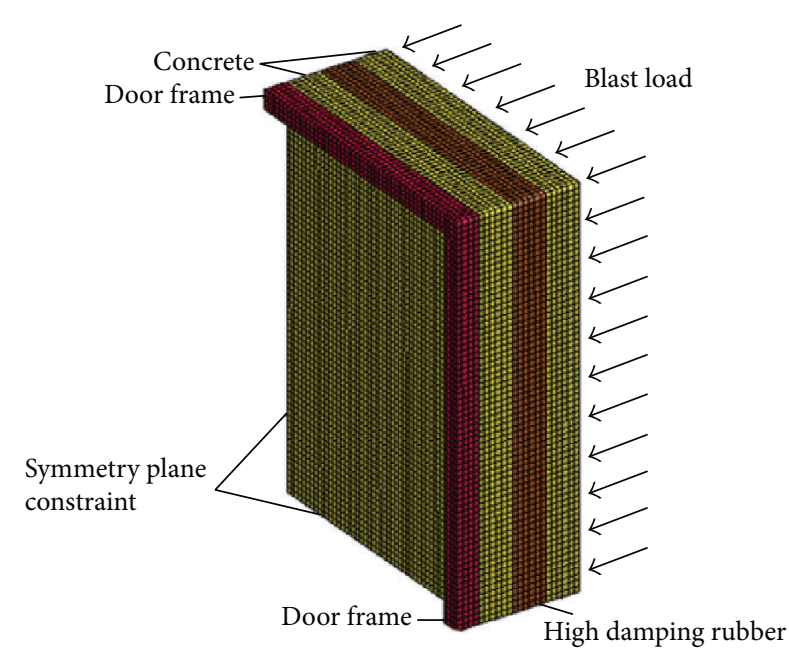

Interlayered high-damping-rubber blast door

FIGURE 3: Finite element models of ordinary and interlayer blast doors.

the door. For the symmetry, the quarter finite element models of the ordinary and interlayer blast doors are established and shown in Figure 3.

\subsection{Material Model}

3.2.1. Concrete. There are numerous material models which could be used to simulate the behavior of concrete under blast and shock in LS-DYNA finite element code, such as CONCRETE_DAMAGE_REL3 (MAT_72REL3), WINFRITH_ CONCRETE_REINFORCEMENT (MAT_84), JOHNSON HOLM-QUIST_CONCRETE (MAT_111), and CSCM_CONCRETE (MAT_159). Reference [11] compared many concrete models and showed that the CONCRETE_DAMAGE_REL3 model could simulate the dynamic behavior of concrete well. So, the CONCRETE_ DAMAGE_REL3 model is used in the present research. It is a three-invariant model, uses three shear failure surfaces, and includes the damage and strain rate effect [12]. The major advantage of this model is that its parameter input is simple which only needs the unconfined compressive strength, the density, and Poisson's ratio. The remaining parameters are automatically calculated by a builtin algorithm and they can also be modified by the user. In this study, the unconfined compressive strength of concrete is $40 \mathrm{MPa}$, the density is $2.4 \times 10^{3} \mathrm{~kg} / \mathrm{m}^{3}$, and Poisson's ratio is 0.2. To use this model, an equation of state EOS_TABULATED_COMPACTION (EOS 8) must be defined.

Dynamic Increase Factor for both the concrete compressive strength (CDIF) and tensile strength (TDIF) is defined according to the equation recommended by CEB-FIP Model Code 1990 [13, 14]. For concrete compressive strength,

$$
\mathrm{CDIF}=\frac{f_{d c}}{f_{c}}= \begin{cases}\left(\frac{\dot{\varepsilon}}{\dot{\varepsilon}_{\text {stat }}}\right)^{1.026 \alpha}, & \dot{\varepsilon}_{\text {stat }}<\dot{\varepsilon} \leq 30 \mathrm{~s}^{-1}, \\ \gamma\left(\frac{\dot{\varepsilon}}{\dot{\varepsilon}_{\text {stat }}}\right)^{1 / 3}, & 30 \mathrm{~s}^{-1}<\dot{\varepsilon}<300 \mathrm{~s}^{-1},\end{cases}
$$

where $f_{d c}$ is the dynamic compressive strength at strain rate $\dot{\varepsilon}, f_{c}$ is the static compressive strength at $\dot{\varepsilon}_{\text {stat }}, \dot{\varepsilon}_{\text {stat }}=30 \times$ $10^{-6} \mathrm{~s}^{-1}, \alpha=\left(5+9 f_{c} / 10\right)^{-1}$, and $\log \gamma=6.156 \alpha-2$.

For concrete tensile strength,

$$
\mathrm{TDIF}=\frac{f_{d t}}{f_{t}}= \begin{cases}\left(\frac{\dot{\varepsilon}}{\dot{\varepsilon}_{\text {stat }}}\right)^{1.016 \alpha}, & \dot{\varepsilon}_{\text {stat }}<\dot{\varepsilon} \leq 30 \mathrm{~s}^{-1}, \\ \beta\left(\frac{\dot{\varepsilon}}{\dot{\varepsilon}_{\text {stat }}}\right)^{1 / 3}, & 30 \mathrm{~s}^{-1}<\dot{\varepsilon}<300 \mathrm{~s}^{-1}\end{cases}
$$

where $f_{d t}$ is the dynamic tensile strength at strain rate $\dot{\varepsilon}, f_{t}$ is the static compressive strength at $\dot{\varepsilon}_{\text {stat }}, \dot{\varepsilon}_{\text {stat }}=3 \times 10^{-6} \mathrm{~s}^{-1}$, $\alpha=\left(10+6 f_{t} / 10\right)^{-1}$, and $\log \beta=7.112 \alpha-2.33$.

3.2.2. Steel. The reinforcement within the blast door is represented by the material model of MAT_PLASTIC_KINEMATIC (MAT3) from LS-DYNA in this paper. It is a strain sensitive uniaxial elastic-plastic material and it is a very cost effective model which is available for beam elements. Dynamic Increase Factor (DIF) for reinforcement steel proposed by Malvar is used in this study as follows [15]:

$$
\mathrm{DIF}=\frac{f_{d y}}{f_{y}}=\left(\frac{\dot{\varepsilon}}{10^{-4}}\right)^{\alpha}, \quad 10^{-4} \mathrm{~s}^{-1} \leq \dot{\varepsilon} \leq 255 \mathrm{~s}^{-1},
$$

where $f_{d y}$ is the dynamic strength at strain rate $\dot{\varepsilon}, f_{y}$ is the static strength at $\dot{\varepsilon}_{\text {stat }}, \dot{\varepsilon}_{\text {stat }}=10^{-2} \mathrm{~s}^{-1}$, for the yield stress, $\alpha=$ $0.074-0.040 f_{y} / 414$, for the yield stress, and $\alpha=0.019-$ $0.009 f_{y} / 414$.

The parameters of reinforcement are shown in Table 1.

3.2.3. High Damping Rubber. A two-parametric material model for rubber of MOONEY-RIVLIN_RUBBER (MAT 27) 
TABLE 1: Parameters of reinforcement steel.

\begin{tabular}{lcccc}
\hline Density $\rho\left(\mathrm{kg} / \mathrm{m}^{3}\right)$ & Poisson ratio $\mu$ & Elasticity modulus $E(\mathrm{MPa})$ & Yield strength $f_{y}(\mathrm{MPa})$ & Failure strain \\
\hline $7.83 \times 10^{3}$ & 0.3 & $2 \times 10^{5}$ & 335 & 0.12 \\
\hline
\end{tabular}

is defined for high damping rubber in this paper. The strain energy density function [12] is defined as

$$
\begin{aligned}
W= & A(\mathrm{I}-3)+B(\mathrm{II}-3)+C\left(\mathrm{III}^{-2}-1\right) \\
& +D(\mathrm{III}-1)^{2}, \\
C= & 0.5 A+B, \\
D= & \frac{A(5 v-2)+B(11 v-5)}{2(1-2 v)},
\end{aligned}
$$

where $v$ is the Poisson ratio; $2(A+B)$ is the shear modulus of linear elasticity; I, II, and III are invariants of right CauchyGreen Tensor.

$A$ and $B$ are needed for this model to simulate the behavior of high damping rubber under explosion. This also provides a built-in algorithm of the least square fit to calculate the coefficients $A$ and $B$ when there is a nominal engineering stress-strain curve within this model. So, the engineering stress-strain curve obtained from the SHPB experiment (see Figure 2) was input in this model. The Poisson ratio and the density of high damping rubber are 0.499 and $1.35 \times$ $10^{3} \mathrm{~kg} / \mathrm{m}^{3}$ by measuring, respectively.

3.3. Boundary Condition. Simple support or setting contact is usually considered for the boundary condition of blast door. Yang et al. analyzed the dynamic response of blast door in different boundary condition and results showed that simple support is safe enough in blast door calculating [16]. $\mathrm{Lu}$ studied the dynamic response of blast door by setting contact between the door and door frame as well as the contact between the door shaft and bearing bush. They also obtained the bounce of blast door by this method [17]. In fact, the hinge mechanism of blast door is not required to bear force under the shock wave positive phase. Thus, in this paper, considering the actual bearing of blast door, the contact of "Automatic Contact, Surface to Surface" in LSDYNA program was set between the door and door frame.

3.4. Blast Load. The thermobaric shock wave can be applied to blast door by fluid-structure coupling algorithm and loading curve directly. Fluid-structure coupling algorithm was used to calculate the dynamic response of structure under close-in explosions [18]. The number of model elements would be too large to calculate for computer using fluidstructure coupling algorithm in this study. Loading shock wave curve directly on blast door as area uniform load has been widely applied to the research of dynamic response of blast door under explosion and shock [17]. So, this method is chosen in the present study.

Three-dimensional numerical calculation model of blast wave in tunnel was established with the software ANSYS/LSDYNA based on the test data of explosion in tunnel entrance

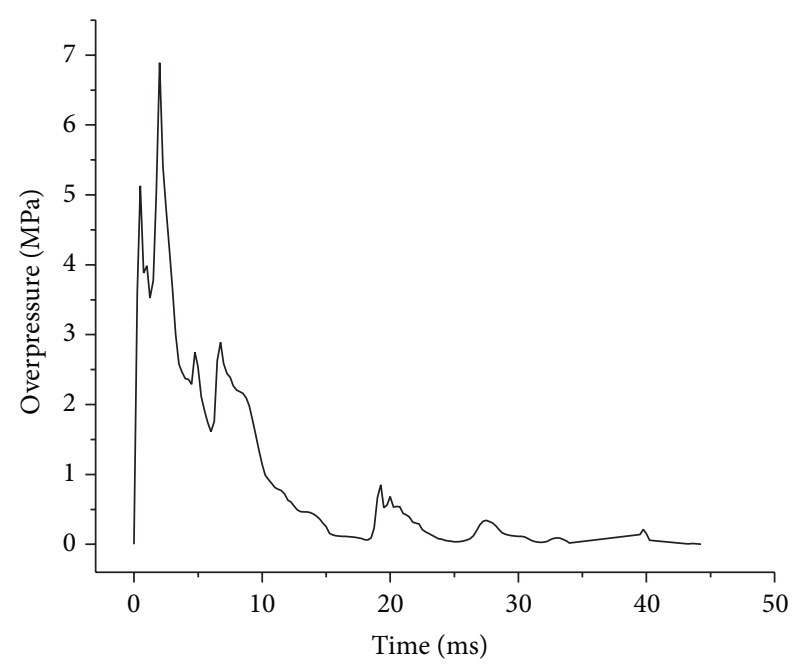

FIgURE 4: Waveform of TBE explosion in $10 \mathrm{~m}$ from blast door.

[19]. One kind of RDX-based thermobaric explosive (denoted as TBE) weighting at $75 \mathrm{~kg}$ was calculated by this model [20]. The law of shock wave propagation in tunnel was obtained and the reflected overpressure is $6.88 \mathrm{MPa}$; the reflected impulse is $35.43 \mathrm{MPa} \cdot \mathrm{ms}$ in the distance of $10 \mathrm{~m}$ from tunnel entrance. Ignoring the influence of the shock wave negative phase, the waveform of thermobaric explosive after filtering is shown in Figure 4.

3.5. Mesh Sensitivity Analysis. Since the mesh size is important to the accuracy of the calculation results, the mesh size of 30,15 , and $10 \mathrm{~mm}$ is chosen to study the mesh sensitivity in this research. The blast load shown in Figure 4 was applied to the blast doors and the calculation results with different mesh size are shown in Figure 5.

Figure 5 shows that, with decrease of the mesh size, the midspan displacements of both the ordinary door and the interlayer door increase gradually. They are 333.8, 451.1, and $460.2 \mathrm{~mm}$, respectively, of ordinary door and 79.1, 114.3, and $118.4 \mathrm{~mm}$, respectively, of interlayer door with mesh size of 10,15 , and $30 \mathrm{~mm}$. The error is $27.5 \%$ and $2.0 \%$ with the mesh size of 30 and $15 \mathrm{~mm}$ in contrast with the mesh size of $10 \mathrm{~mm}$ for ordinary door. For interlayer door, it is $29.8 \%$ and $3.4 \%$, respectively. Thus, the $15 \mathrm{~mm}$ mesh size of the two kinds of blast door is selected in view of the accuracy and calculation time. The number of elements for concrete and steel reinforcement of ordinary door is 3180 and 61200 , respectively, and the number of elements for concrete and steel reinforcement and rubber of interlayer door is 3288 and 34000 and 34000 , respectively.

3.6. Model Validation. To validate the accuracy and reliability of the model proposed in this paper, the test NSC-NR case in 


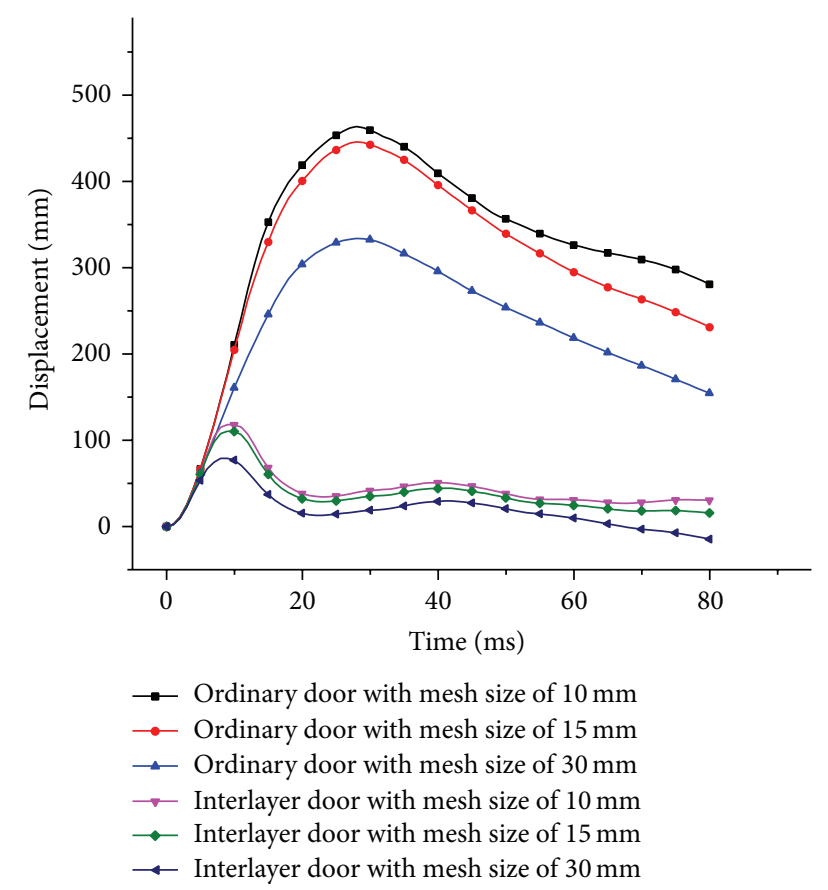

FIGURE 5: The effect of different mesh size on midspan displacement of blast door.

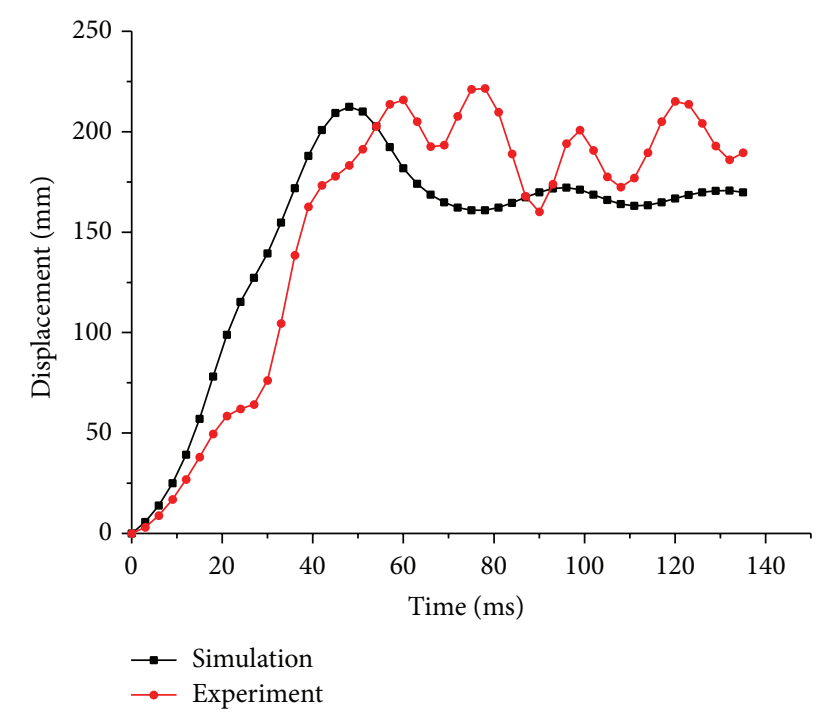

Figure 6: The history curves of midspan displacement from experiment and simulation.

[21] was simulated with the method proposed above in this study. The history curves of midspan displacement from both experiment and simulation are shown in Figure 6.

Figure 6 shows that the history curve of midspan displacement from simulation achieved good consistency with the experiment. The maximum value of midspan displacement from simulation is $212.7 \mathrm{~mm}$ whose error is $3.76 \%$ with the test value of $221 \mathrm{~mm}$. It shows that the numerical model proposed by this paper can simulate the dynamic response of reinforced concrete doors well under blast loading.

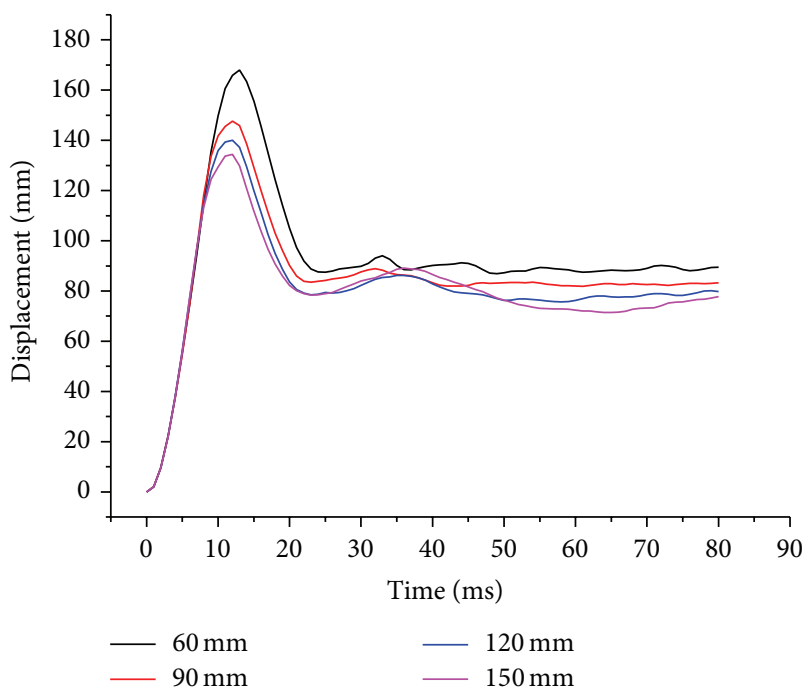

(a) History curves of midspan displacement

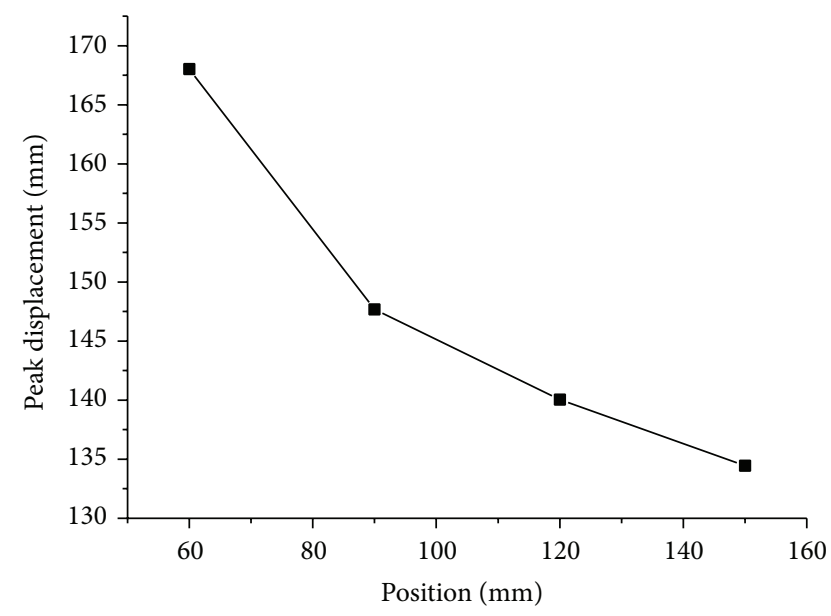

(b) Relationship between peak displacement and position of interlayer

FIGURE 7: Effect of interlayer position on the displacement of blast door.

\section{Optimization Design of Interlayer Blast Door}

In order to achieve the optimal protective effect against thermobaric shock wave, the influence of interlayer position and thickness of the high damping rubber on antiknock performance are studied in this section and the blast door is optimized according to the results.

4.1. Position of Interlayer. Because of the complex stress of blast door under blast, the different positions of interlayer of the high damping rubber in blast door will affect its energy absorption capacity. So, the thickness of the blast door and the interlayer is kept at $300 \mathrm{~mm}$ and $90 \mathrm{~mm}$, respectively. But the interlayer is set at $60,90,120$, and $150 \mathrm{~mm}$, respectively, from the front surface of the door to study the influence of the interlayer position on the antiknock performance. The midspan displacement history curves of the door and the relationship between the peak displacements and interlayer positions in all conditions are shown in Figure 7. 
Figure 7 shows that with the increase of the distance between interlayer and front surface of blast door, the peak displacement and residual displacement decline somewhat. It is because the back surface of blast door is in tension and the tensile strength of high damping rubber is greater than concrete. So the flexural capacity of blast door is enhanced with the increase of the distance between interlayer and front surface. For example, the peak displacement is $134.4 \mathrm{~mm}$ when the distance is $150 \mathrm{~mm}$ which decreases by $20.0 \%$ in comparison with the case when it is $60 \mathrm{~mm}$ (peak displacement is $168.0 \mathrm{~mm}$ ). That shows the antiknock performance of the door will be increased if the position of interlayer is set far away from the front surface properly.

4.2. Thickness of Interlayer. If the rubber interlayer is thin enough, the energy of blast wave would not be absorbed adequately. On the contrary, if the rubber interlayer is too thick, stiffness of section of blast door will decrease greatly which will weaken the bend and shear capacity of blast door owing to the lower modulus of rubber. So, the thickness of blast door is kept at $300 \mathrm{~mm}$ and the thickness of interlayer is set at $30,60,90,120,150$, and $180 \mathrm{~mm}$ to study the effect of interlayer thickness on the antiknock performance. The midspan displacement history curve and the relationship between peak displacement and interlayer thickness in all conditions are shown in Figure 8.

Figure 8(a) shows that when the thickness of interlayer is less than $150 \mathrm{~mm}$, with the increase of interlayer thickness, both the peak displacement and the residual displacement decrease continuously. For example, Figure 8(b) shows that the peak midspan displacement is $114.9 \mathrm{~mm}$ when the thickness of interlayer is $150 \mathrm{~mm}$ which decreases $39.3 \%$ in comparison with the case when thickness of interlayer is $30 \mathrm{~mm}$ (peak midspan displacement is $189.3 \mathrm{~mm}$ ). That shows the midspan displacement will effectively decrease with adding the thickness of interlayer when the thickness of interlayer is less than $150 \mathrm{~mm}$. However, when the thickness of interlayer is $180 \mathrm{~mm}$, the peak displacement is $118.9 \mathrm{~mm}$ which is a little greater than the case which is $150 \mathrm{~mm}$. So, $150 \mathrm{~mm}$ is recommended as the optimum thickness of interlayer in this paper.

\section{Antiknock Performance of Interlayer Blast Door}

5.1. Displacement and Rotation. According to the optimization design results mentioned above, the total thickness of interlayered high-damping-rubber blast door is $300 \mathrm{~mm}$ and the thickness of interlayer is $150 \mathrm{~mm}$ set in the middle of the reinforced concrete door. The whole weight of the interlayer door is about $1.9 \mathrm{t}$ which is lighter than the ordinary reinforced concrete door of $270 \mathrm{~mm}$ (about $2.2 \mathrm{t}$ ). The waveform from Figure 4 was loaded on the blast door directly. For the convenience of comparison, the ordinary reinforced concrete blast door of $300 \mathrm{~mm}$ in thickness is also calculated. The history curve of midspan displacement is shown in Figure 9.

Figure 9 shows that the midspan displacement of three kinds of blast doors increases quickly at first and then reduces gradually with time. In the initial impact phase of blast wave,

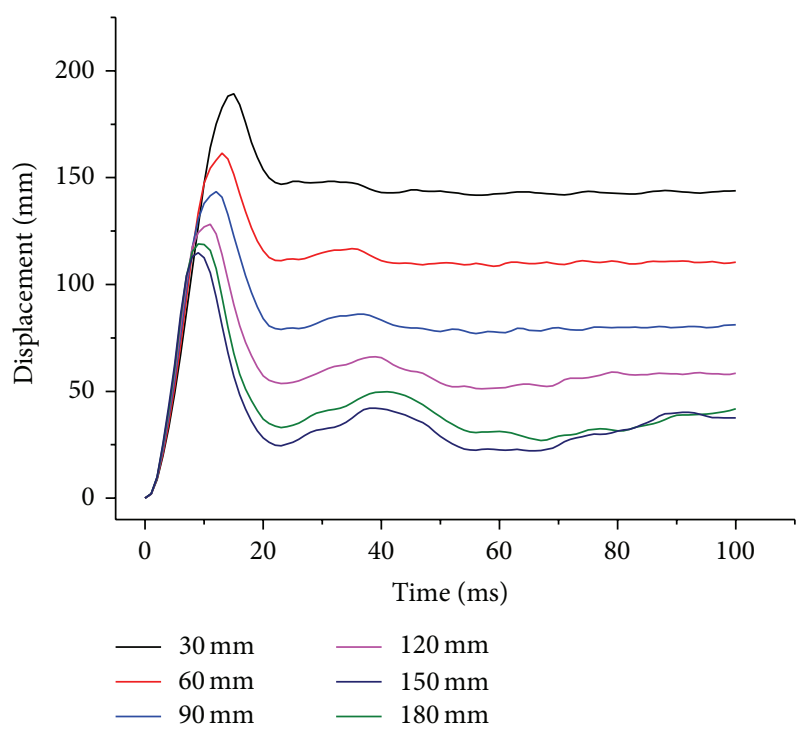

(a) History curve of midspan displacement

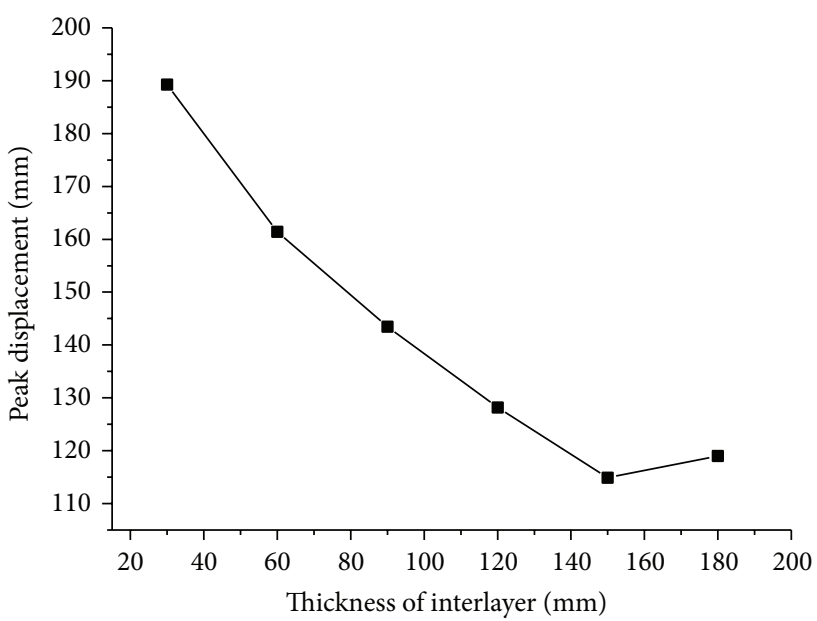

(b) Relationship between peak displacement and thickness of interlayer

FIGURE 8: Effect of interlayer thickness on the displacement of blast door.

before the midspan displacement of blast door reaching the maximum, the midspan displacement of interlayered highdamping-rubber blast door increases most rapidly because of the lower elastic modulus of rubber and a lot of energy of blast wave was consumed during this phase.

The maximum midspan displacements of the three blast doors are $451.1 \mathrm{~mm}, 257.3 \mathrm{~mm}$, and $114.9 \mathrm{~mm}$ respectively. The maximum displacement of interlayered high-dampingrubber blast door decreases by $74.5 \%$ and $55.3 \%$ compared to the $0.27 \mathrm{~m}$ and $0.3 \mathrm{~m}$ ordinary blast door, respectively. It shows that the deformation of the blast door with the high damping rubber will effectively decrease. The rotation $\theta$ at blast door bearing can be calculated as follows:

$$
\theta=\arctan \left(\frac{X}{B / 2}\right)
$$




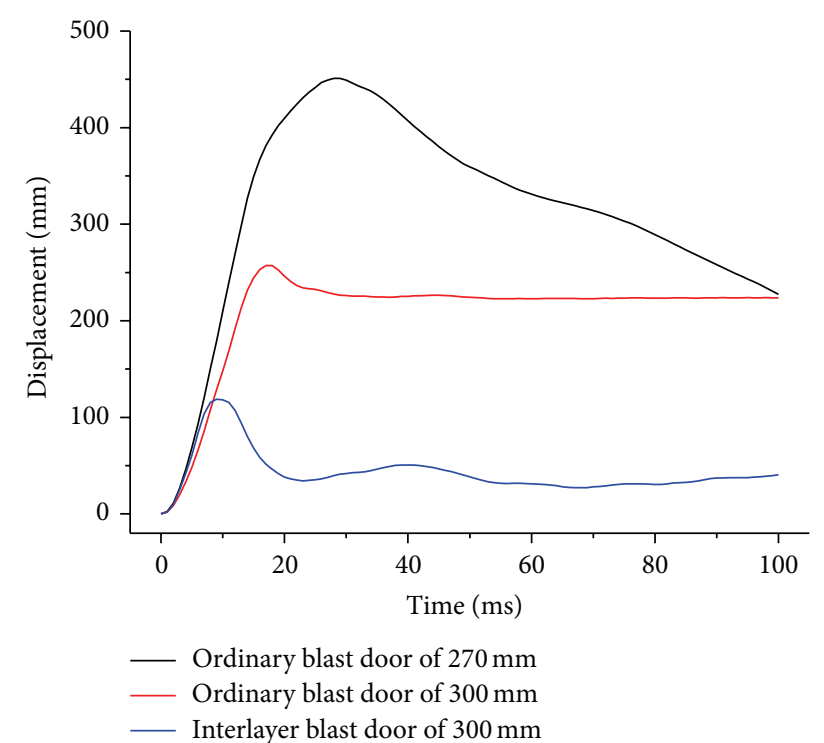

FIGURE 9: History curve of midspan displacement of different doors.

where $X$ is the maximum midspan displacement of blast door; $B$ is the width of blast door.

The rotation is $31.0^{\circ}, 18.9^{\circ}$, and $8.7^{\circ}$, respectively, obtained with plugging the maximum midspan displacement of blast door into (8). According to [22], the reinforced concrete flexural members will lose the integrity and will be destroyed completely when the rotation reaches $12^{\circ}$. So, not only is the interlayered high-damping-rubber blast door light-weight, but it can also prevent the destruction from the blast wave of thermobaric bomb at the calculation conditions of this paper.

5.2. Energy Analysis of the Components. The energy of the total door and each component of $270 \mathrm{~mm}$ ordinary blast door and interlayered high-damping-rubber blast door under thermobaric blast wave are shown in Figure 10, respectively.

Figure 10 shows that the total energy of ordinary blast door is $138.4 \mathrm{~kJ}$ and that of interlayer blast door is $59.6 \mathrm{~kJ}$ which decreases by $56.9 \%$. Due to the existence of highdamping-rubber interlayer, some energy of blast wave is absorbed and a part of energy is consumed by reflection during the propagation of blast wave in interlayer interface. It is easy to make a conclusion that the security of blast door is enhanced effectively after adding the high-damping-rubber interlayer in it.

For ordinary reinforced concrete blast door, concrete and reinforced bars are the energy-consuming components. The fracture of reinforced bars will directly threaten the overall completeness of blast door under the impact of blast wave. Figure 10(b) shows that a lot of energy is absorbed by high damping rubber interlayer in the initial impact phase of blast wave by which the energy absorbed by reinforced bar decreases greatly. The energy absorbed by concrete, tensile reinforcement, and distributing reinforcement decrease by $63.9 \%, 73.9 \%$, and $70.9 \%$, respectively, in comparison with

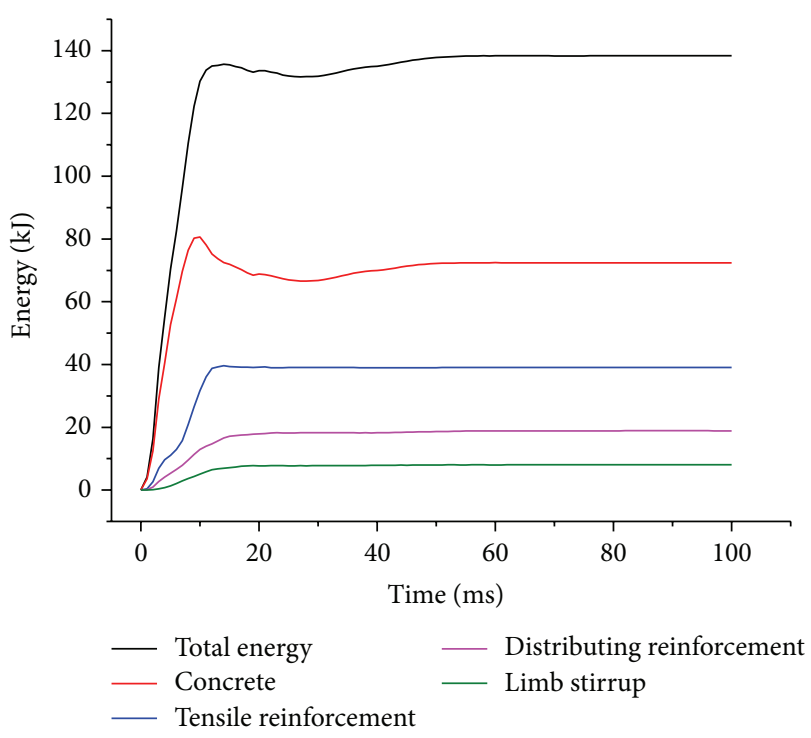

(a) Ordinary reinforced concrete blast door

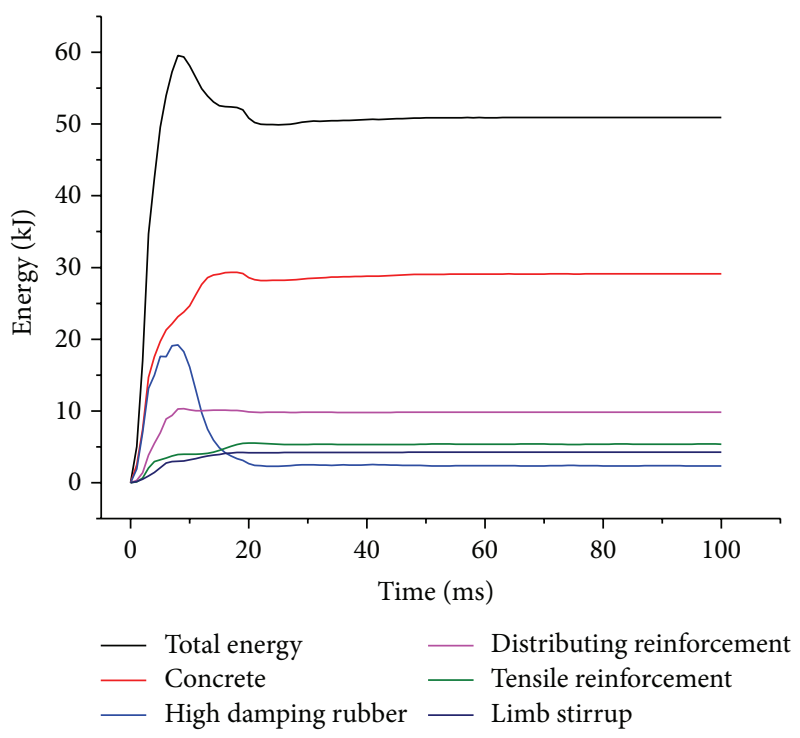

(b) Interlayered high-damping-rubber blast door

FIGURE 10: Distribution of energy of blast door.

the ordinary blast door. The energy absorption role of high damping rubber is a good protection for the concrete and rebar of blast door.

\section{Conclusions}

To obtain high resistance blast door against shock wave with longer duration and higher impulse from the thermobaric bomb, the dynamic mechanic property of high damping rubber was studied by split Hopkinson pressure bar (SHPB) equipment. The numerical model of interlayered highdamping-rubber blast door under thermobaric shock wave was established based on test results. The interlayer blast door is optimized by studying the influence factor. The antiknock performance of interlayered high-damping-rubber blast 
door was analyzed by contrast with ordinary blast door. Some conclusions are drawn as follows:

(1) The stress-strain relationship of high damping rubber under the high strain rate of 5200/s was obtained, which provides the basis and foundation for the study of the energy absorption of high damping rubber under thermobaric shock wave.

(2) With the increase of the thickness of interlayer, the midspan displacement decreases at first and then increases, and the optimal thickness of the interlayer is $150 \mathrm{~mm}$ in the calculation condition of this paper. With the increase of the distance between the interlayer and front surface of the door, the midspan displacement of the blast door decreases continually.

(3) The midspan displacement of interlayered highdamping-rubber blast door decreases by $74.5 \%$ and the energy absorbed by concrete, tensile reinforcement, and distributing reinforcement decreased by $63.9 \%, 73.9 \%$, and $70.9 \%$, respectively, in comparison with ordinary blast door. It shows that the highdamping-rubber structure can effectively improve the antiknock performance of blast door.

\section{Competing Interests}

The authors confirm that this paper's content has no conflict of interests.

\section{Acknowledgments}

The SHPB experiment was provided by Hefei University of Technology in China. The authors would like to thank Dr. Mrs. Baozhen Wang for her assistance in conducting the experiments.

\section{References}

[1] Y. D. Zhang, Research on dynamic and static characteristic of large scale high strength concrete filled steel tubular composite door, PLA University of Science and Technology, Nanjing, China, 2006 (Chinese).

[2] S. Q. Shi, X. Y. Zhang, and P. Yin, "Static analysis of the new defensive structure under explosive loading," Chinese Journal of Underground Space and Engineering, vol. 23, no. 5, pp. 66-68, 2003 (Chinese).

[3] M. Z. Hassan, Z. W. Guan, W. J. Cantwell, G. S. Langdon, and G. N. Nurick, "The influence of core density on the blast resistance of foam-based sandwich structures," International Journal of Impact Engineering, vol. 50, pp. 9-16, 2012.

[4] Z. Fan, Y. Liu, and P. Xu, "Blast resistance of metallic sandwich panels subjected to proximity underwater explosion," International Journal of Impact Engineering, vol. 93, pp. 128-135, 2016.

[5] Z. G. Ren, M. L. Lou, and Z. M. Tian, "Analysis of antidetonational property of sandwich panel of ployurethane foam," Chinese Journal of Tongji University, vol. 31, no. 5, pp. 6-10, 2003 (Chinese).
[6] J. Q. Fan, K. Xin, H. M. Song et al., "Experimental study of the mechanism of foam sandwich material in an antiblast composite structure," Chinese Journal of Experimental Mechanics, vol. 26, no. 3, pp. 329-336, 2011 (Chinese).

[7] Y. Yuan, K. Zhu, S. H. Xiong et al., "Experimental study on characteristics and isolator effect of high-damping rubber bearing," Chinese Journal of Earthquake Resistant Engineering and Retrofitting, vol. 30, no. 3, pp. 15-20, 2008 (Chinese).

[8] Y.-J. Chen, K.-M. Guo, Y. Li, and F. Chen, "Behavior of high damping seismic isolation rubber bearings for bridges," Chinese Journal of Vibration and Shock, vol. 34, no. 9, pp. 136-148, 2015 (Chinese).

[9] J. G. Ning, C. Wang, and T. B. Ma, Explosion and Shock Dynamics, National Defense Industry Press, Beijing, China, 2012.

[10] B. Z. Wang, S. S. Hu, and X. R. Zhou, "Research of dynamic mechanical behavior and constitutive model of rubber under different temperatures," Chinese Journal of Experimental Mechanics, vol. 22, no. 1, pp. 1-6, 2007 (Chinese).

[11] Z. G. Tu and Y. Lu, "Evaluation of typical concrete material models used in hydrocodes for high dynamic response simulations," International Journal of Impact Engineering, vol. 36, no. 1, pp. 132-146, 2009.

[12] Livermore Sotware Technology Corporation, LS-DYNA Keyword User's Manual (Version 971 R6.1.0), Livermore Sotware Technology Corporation, Livermore, Calif, USA, 2012.

[13] B. C. E.-I. Du, CEB-FIP Model Code 1990, Redwood Books, Trowbridge, UK, 1990.

[14] J. Li and H. Hao, "Numerical study of concrete spall damage to blast loads," International Journal of Impact Engineering, vol. 68, pp. 41-55, 2014.

[15] L. J. Malvar, "Review of static and dynamic properties of steel reinforcing bars," ACI Materials Journal, vol. 95, no. 5, pp. 609616, 1998.

[16] X. Y. Yang, Y. T. Zhao, and Z. X. Zhou, "Dynamic response of blast door under different forms of constrains," Chinese Journal of Blasting, vol. 31, no. 2, pp. 47-56, 2014 (Chinese).

[17] X. Z. Lu and J. J. Jiang, "Safety assessment of blast-resistant doors using dynamic finite element method and contact analysis," Chinese Journal of Mechanics in Engineering, vol. 25, no. 2, pp. 24-26, 2003 (Chinese).

[18] S. F. Gong, H. Deng, S. B. Zhu et al., "Numerical simulation for dynamic failure of a reinforced concrete slab under close-in explosion," Chinese Journal of Vibration and Shock, vol. 31, no. 2, pp. 20-24, 2012 (Chinese).

[19] C. Y. Miao, X. D. Li, W. Sun et al., "Three-dimensional numerical simulation and experimental verification of blast wave in Tunnel," Chinese Journal of Logistical Engineering University, vol. 31, no. 5, pp. 20-24, 2015 (Chinese).

[20] C. Y. Miao, X. D. Li, S. Yang et al., "Comparative study of blast wave of thermobaric explosive and TNT in tunnel," in Proceedings of the National Conference on Damage Assessment Techniques, pp. 499-505, Beijing, China, 2015 (Chinese).

[21] G. Thiagarajan, A. V. Kadambi, S. Robert, and C. F. Johnson, "Experimental and finite element analysis of doubly reinforced concrete slabs subjected to blast loads," International Journal of Impact Engineering, vol. 75, pp. 162-173, 2015.

[22] TM5-1300, The Design of Structures to Resist the Effects of Accidental Explosions, Technical Manual, US Department of the Army, Navy, and Air Force, Washington, Wash, USA, 1990. 


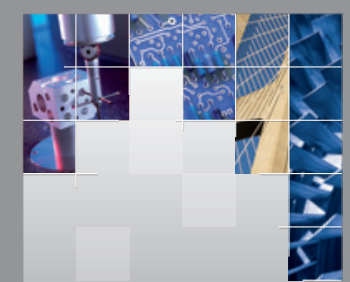

\section{Enfincering}
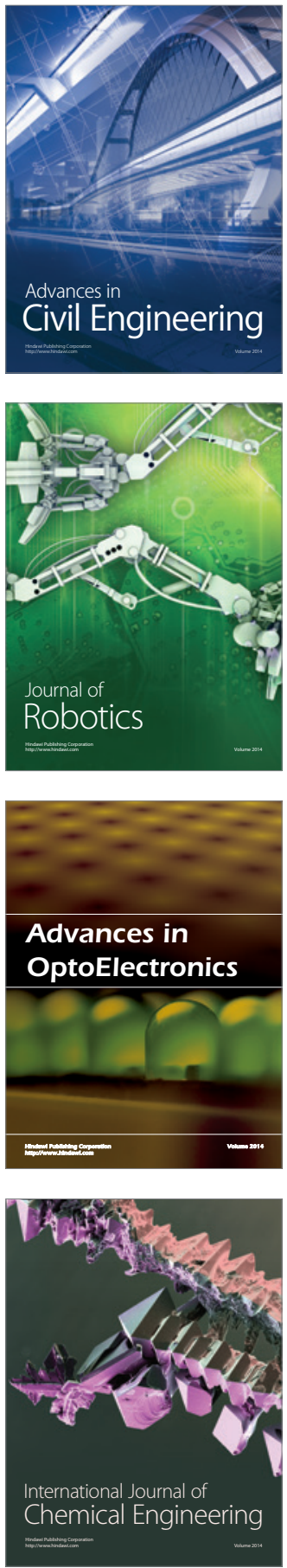

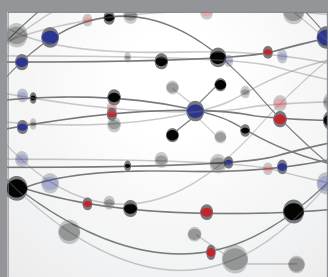

The Scientific World Journal

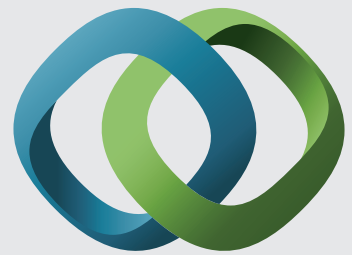

\section{Hindawi}

Submit your manuscripts at

http://www.hindawi.com
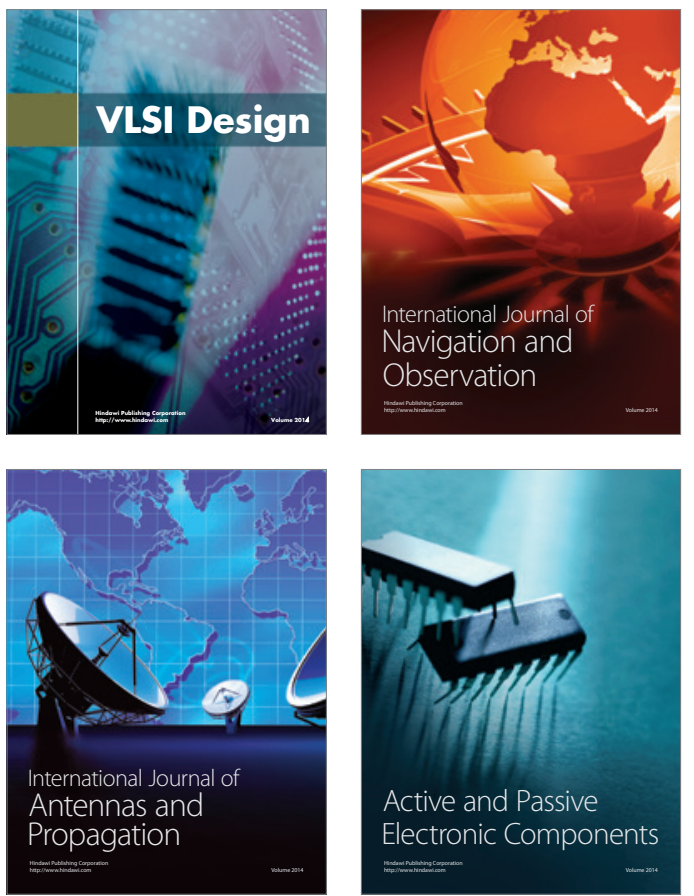
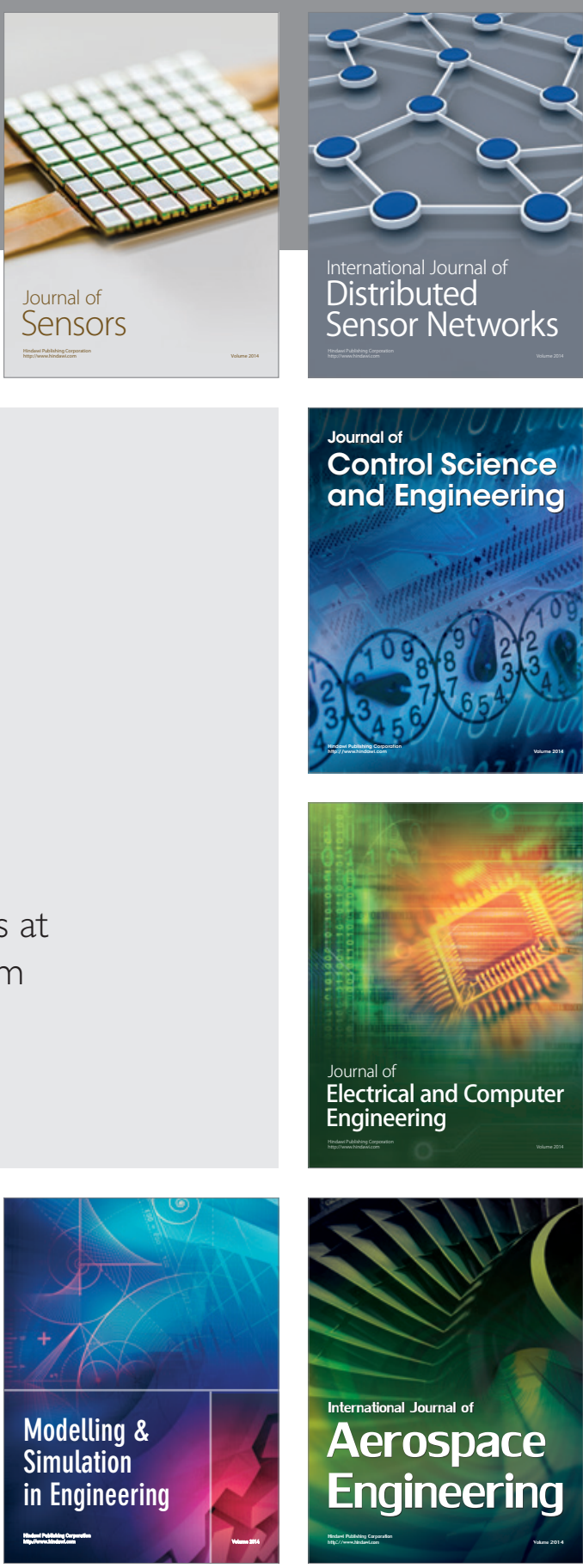

International Journal of

Distributed

Sensor Networks

Journal of

Control Science

and Engineering
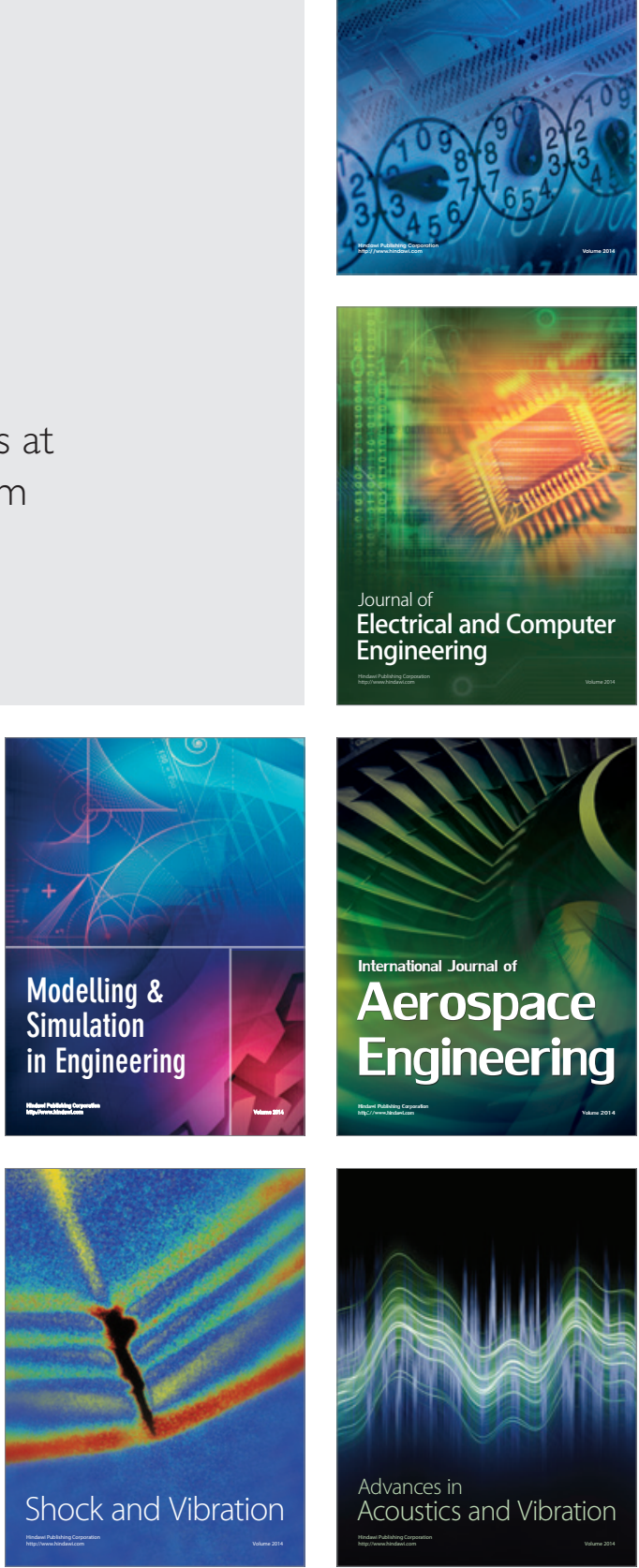